\title{
Linfoma não-Hodgkin, manifestação no sistema estomatognático - Relato de caso clínico
}

\section{Non-Hodgkin lymphoma, manifestation in the stomatognathic system - clinical case report}

\author{
Rita Fabiane Teixeira Gomes, José Luiz Piazza, Edilson Fernando Castelo
}

Como citar este artigo: COMES, Rita F. T.; PIAZZA, José L.; CASTELO, Edilson F.; Linfoma nãoHodgkin, manifestação no sistema estomatognático - Relato de caso clínico Revista Saúde (Sta. Maria). 2019; 45 (3).

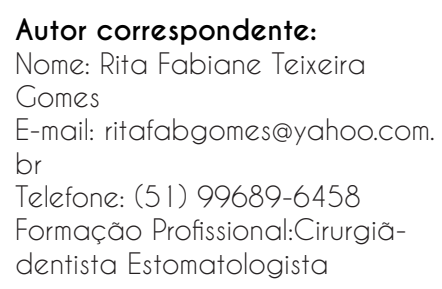

Filiação Institucional: Hospital Santa Cruz. Ex Residente do Programa de Residencia Multiprofissional dos cursos da saúde, área de concentração: Urgência, Intensivismo e Trauma.

Endereço para correspondência: Borges de Medeiros n 534, sala 304

Bairro: Centro

Cidade: Santa Cruz do Sul

Estado: Rio Grande do Sul

CEP: $96810-034$

Data de Submissão:

01/05/2018

Data de aceite:

$16 / 12 / 2019$

Conflito de Interesse: Não há conflito de interesse

\section{(cc) BY-NC-ND}

\section{RESUMO}

Linfomas são transformações neoplásicas de células linfoides, o Linfoma Não-Hodgkin raramente ocorre na cavidade oral, os casos intraorais podem manifestar-se como inchaço, dor, dormência, mobilidade dentária ou linfadenopatia cervical, os achados radiográficos podem assemelhar-se a osteomielites, neoplasias secundárias ou lesões odontogênicas. Pode ocorrer aumento de volume em tecido mole e não cicatrização após extrações dentárias - sinais suspeitos de malignidade. Os linfomas são lesões malignas agressivas, com alto potencial de cura através de quimioterapia associada ou não à radioterapia, se diagnosticados precocemente. A cirurgia geralmente não é indicada. 0 prognóstico é bom para doenças localizadas, sendo menos favorável para doença disseminada. Cabe ao cirurgiãodentista diagnosticar manifestações estomatognáticas, contribuindo para o tratamento médico efetivo. O objetivo deste estudo é o relato de caso clínico de paciente com lesão osteolítica na mandíbula, com diagnóstico de Linfoma não-Hodgkin difuso de grandes células B a partir da investigação clínica multidisciplinar.

PALAVRAS-CHAVE: Equipe Hospitalar de Odontologia; Diagnóstico precoce; Diagnóstico diferencial; Linfoma.

\section{ABSTRACT}

Lymphomas are neoplastic transformations of lymphoid cells, Non-Hodgkin's Lymphoma rarely occurs in the oral cavity, intraoral cases may manifest as swelling, pain, numbness, mobility or cervical lymphadenopathy, radiographic findings may resemble osteomyelitis, neoplasms secondary or odontogenic lesions. Soft tissue volume and non-healing may occur after dental extractions suspicious signs of malignancy. Lymphomas are aggressive malignant lesions, with a high potential for cure through chemotherapy associated or not with radiotherapy, if diagnosed early. Surgery is usually not indicated. The prognosis is good for localized diseases, being less favorable for disseminated disease. It is up to the dental surgeon to diagnose stomatognathic manifestations, contributing to effective medical treatment. The purpose of this study is the clinical case report of a patient with osteolytic lesion in the mandible, with diagnosis diffuse non-Hodgkin's lymphoma of large B cells from the multidisciplinary clinical investigation.

KEYWORDS: Dental staff, hospital; Early diagnosis; Differential diagnosis; Lymphoma. 


\section{INTRODUÇÃO}

Os linfomas são transformações neoplásicas de células linfoides ${ }^{1}$ ou de seus precursores linforreticulares ${ }^{2-7}$. São divididos em Linfoma de Hodgkin (LH) e Linfoma Não-Hodgkin (LNH) ${ }^{1,5-7}$. O LNH comumente ocorre em linfonodos, porém pode ocorrer extranodal, sendo relatado no estômago, glândulas salivares, pele, ossos e raramente na cavidade oral|,69. A manifestação clínica depende de vários fatores como localização, taxa de crescimento do tumor, órgão ou tecido envolvido ou deslocado 4 . O envolvimento bucal frequentemente faz parte da doença generalizada, correspondendo 3,5\% das neoplasias intraorais ${ }^{2,8}$.

Os sinais clínicos do LNH bucal incluem massas ou lesões ulceradas, inchaço, dor, dormência, mobilidade dentária, odontalgia com vitalidade preservada ou linfadenopatia cervical ${ }^{7,9}$. Os achados radiográficos podem ser inespecíficos ${ }^{2,7,9}$. A rápida destruição óssea sem evidência de infecção odontogênica é uma característica dos tumores mandibulares 8,10 .

O diagnóstico de linfoma na cavidade oral pode ser complicado, são indicados exames anatomopatológico e imuno-histoquímico para diferenciar as condições benignas das malignas e estabelecer a subclassificação ${ }^{10}$. 0 tratamento é baseado no estadiamento e grau do linfoma, estado geral de saúde do paciente e história médica pregressa. A cirurgia geralmente não é indicada ${ }^{11}$.

\section{RELATO DE CASO}

Paciente feminina, leucoderma, 49 anos, previamente hígida foi hospitalizada por dor e inchaço no membro inferior esquerdo (MIE), com relato de um mês de evolução e piora progressiva. A paciente negava hábitos de tabagismo ou etilismo, sem relato de perda ponderal recente ou uso sistemático de medicamentos. Apresentava acentuado aumento de volume no MIE, com tumefação pétrea na coxa (Figura 1), sem presença de linfonodos inguinais palpáveis. As hipóteses de diagnóstico iniciais foram trombose venosa profunda poplítea, miosite, trombofilia ou linfoma.

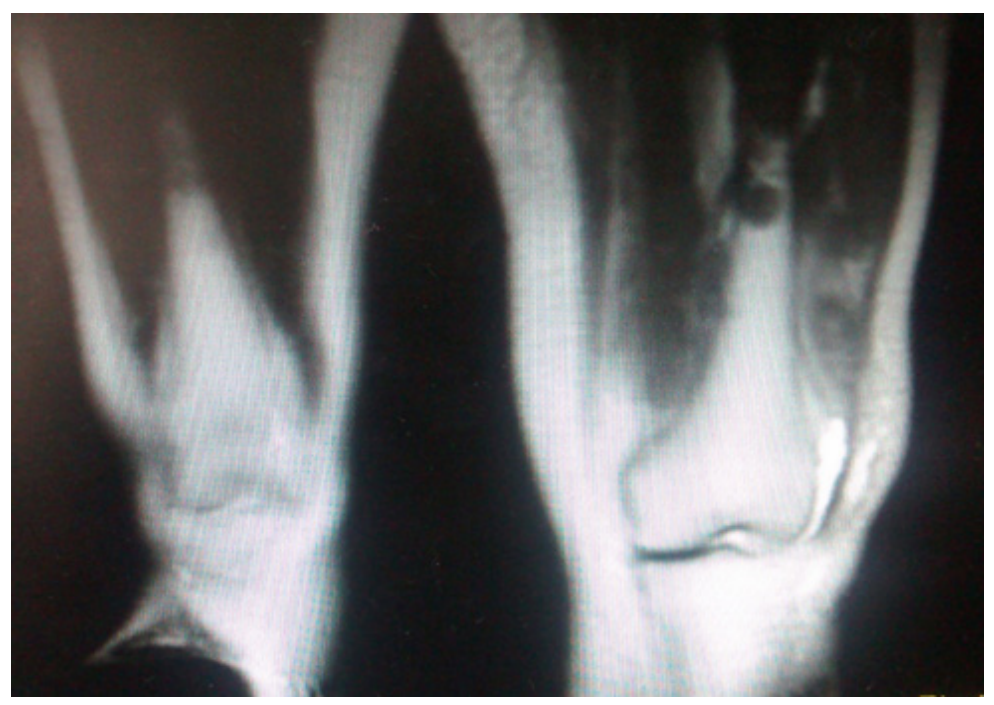

Figura 1 - Ressonância magnética demonstrando o aumento de volume no MIE. 
Durante a internação hospitalar, apresentou queixa de odontalgia, ao exame clínico odontológico, apresentava aumento de volume na face, lado esquerdo (Figura 2), edentulismo parcial superior e inferior, não reabilitado com próteses, apresentava ainda tumefação na lateral do corpo e ramo da mandíbula no lado esquerdo, consistência firme, indolor, apagamento do fundo de sulco e com tempo de evolução indeterminado. Relatava dor no dente 33 que encontrava-se íntegro, com tecidos periodontais saudáveis, testes de percussão e sensibilidade negativos e sensação de parestesia no lábio inferior. Os exames de imagem mostraram lesão osteolítica (figura 3), rompimento da tábua óssea alveolar e região do forame mandibular esquerdo (figura 4), sem linfonodos submandibulares palpáveis. A hipótese de diagnóstico odontológico inicial foi osteossarcoma, linfoma ou mieloma. Foram realizadas biópsias incisionais no MIE, na região do vasto medial da coxa e também no corpo da mandíbula, lado esquerdo, com resultado preliminar de lesão linfoepitelial atípica infiltrativa em ambas as amostras. O exame imuno-histoquímico determinou Linfoma Não-Hodgkin difuso de grandes células B. A paciente foi encaminhada para um centro de Onco-Hematologia para estadiamento e tratamento.

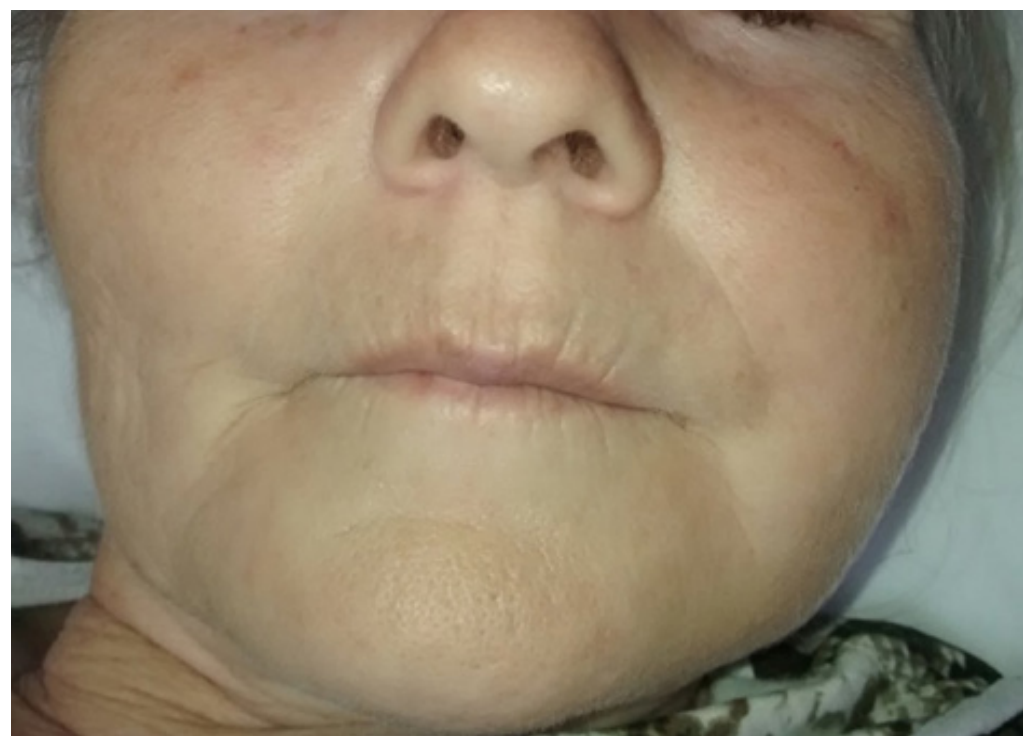

Figura 2 - Imagem do aumento de volume na lateral do corpo da mandíbula, lado esquerdo.

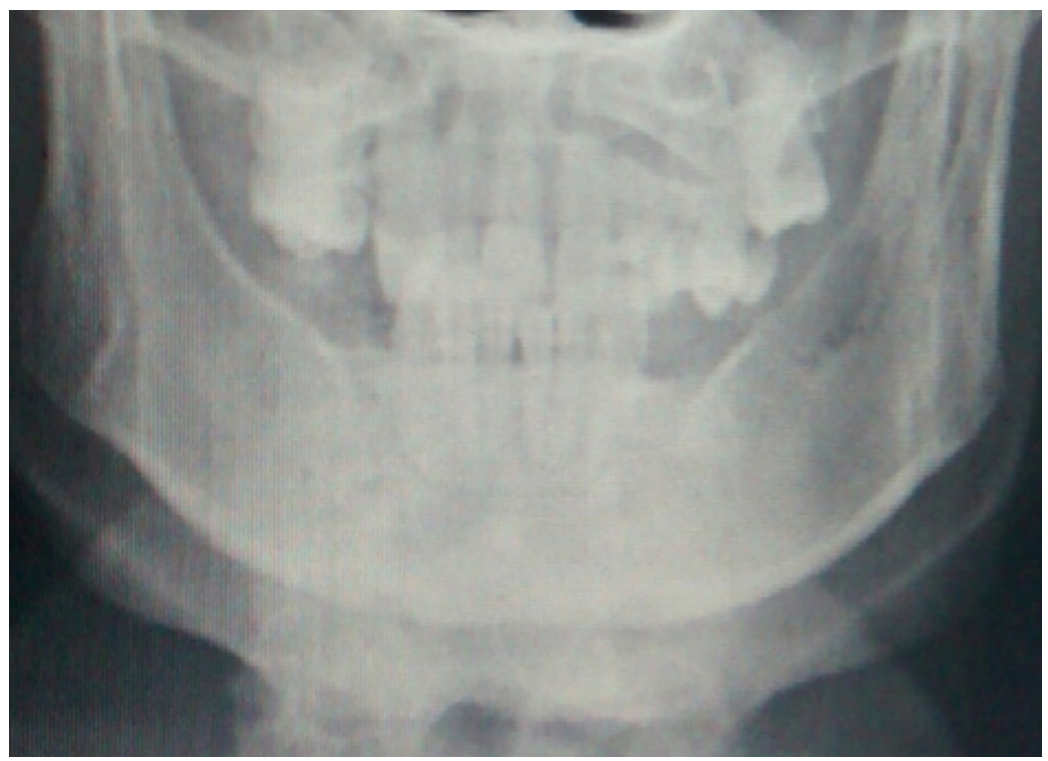

Figura 3 - Radiografia evidenciando lesão osteolítica no corpo da mandíbula, lado esquerdo. 


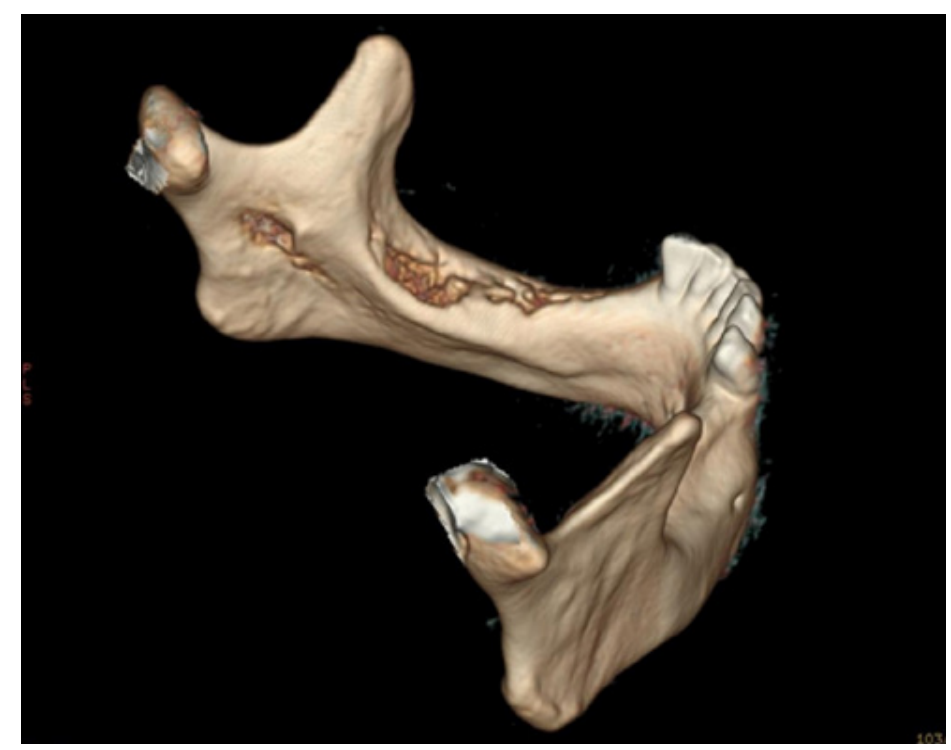

Figura 4 - Tomografia com reconstrução em 3D, que indica áreas de rompimento de cortical óssea alveolar e região do forame mandibular esquerdo

\section{DISCUSSÃO}

O LNH comumente se desenvolve em linfonodo, mas o envolvimento extranodal pode ocorrer-25,8,9, sendo relatada manifestação no estômago, glândulas salivares, pele, ossos e raramente na cavidade oral ${ }^{2-4,6,8,9}$. A ocorrência intraóssea mandibular corresponde a apenas $0,6 \%$ dos $\operatorname{casos}^{4}$. No caso relatado houve envolvimento bucal, mandibular com invasão de tecidos adjacentes e do tecido muscular da coxa esquerda.

Geralmente sem etiologia definida, o LNH pode estar relacionado com fatores hereditários, ambientais, ocupacionais, dietéticos e imunológicos ${ }^{1,11}$. Alguns agentes infecciosos têm sido relacionados, incluindo Vírus da Imunodeficiência Humana (HIV) ${ }^{1,4}$, Epstein-Barr ${ }^{1,5,7}$, herpes tipo 8, hepatite, e bactéria Helicobacter pylori'. Neste caso não foram detectados focos de infecções virais ou bacterianas.

As lesões bucais estão relacionadas a doença disseminada, raramente têm sua primeira manifestação na cavidade oral ${ }^{9,10}$. A localização intraoral mais comum é a gengiva seguida pelo palato, maxila, mandíbula ${ }^{6,8-11}$ amígdala, parótida, língua, lábio, mucosa oral3,8-11, anel de Waldeyer, seios paranasais, tecido laríngeo e estruturas ósseas ${ }^{3,9,11,12}$.

Os primeiros sinais clínicos orais incluem tumefações ou lesões ulceradas justaósseas, podendo apresentar-se intraósseos com extravasamento para tecido mole 2,5,9,10,12. As características clínicas são inespecíficas, podem ocorrer inchaço, dor, parestesia, mobilidade dentária inexplicável ou linfadenopatia cervical. Os achados radiográficos podem ser inespecíficos ${ }^{2,6,9,10,12}$. Conforme este relato, as queixas eram dor no dente 33 que apresentava-se íntegro, sem sinais clínicos que justificassem o sintoma, e dormência no lábio inferior. A partir da radiografia e tomografia computadorizada, identificou-se uma lesão osteolítica, caracterizada por imagem radiolúcida com limites mal definidos, sem expansão 
óssea no corpo da mandíbula, lado esquerdo, com tumefação dos tecidos adjacentes.

A partir dos sinais e sintomas bucais, pode ser difícil realizar o diagnóstico diferencial entre osteomielite, neoplasias secundárias ou lesões odontogênicas ${ }^{4,8,10}$. A rápida destruição óssea local sem evidência de infecção odontogênica é uma característica chave dos tumores de mandíbula ${ }^{8,10}$. Dor persistente, mobilidade dentária causada pela rápida destruição óssea e falha na cicatrização após extrações dentárias podem levar a suspeita de malignidade8. O diagnóstico tardio pode levar à expansão óssea, perfuração da cortical óssea, formação de massa de tecido mole intraoral. Em casos avançados observa-se radioluscência mal definida, aspecto agressivo e rápida evolução ${ }^{8}$ Neste caso, a área de envolvimento mandibular apresentava-se edêntula, não sendo consideradas as lesões odontogênicas no diagnóstico diferencial, não apresentava expansão óssea, porém havia rompimento da cortical óssea alveolar e região do forame mandibular, havia tumefação dos tecidos circunvizinhos e a sensação de parestesia era interpretada pela paciente como dor e edema.

O diagnóstico de linfoma oral pode ser complicado pelo baixo índice de suspeita clínica, sendo indicada a análise anatomapatológica e, tratando-se de linfoma, é necessária imuno-histoquímica para subclassificação ${ }^{5,10}$. A paciente relatou consulta odontológica prévia por dor no dente 33 , porém sem achados com justificativa clínica para a queixa. A partir da identificação de lesão osteolítica mandibular com tumefação adjacente e lesão expansiva de desenvolvimento rápido na coxa esquerda, foram realizadas biópsias incisionais em ambas as lesões, com diagnóstico preliminar de lesão linfoepitelial e a imuno-histoquímica revelou Linfoma não Hodgkin difuso de grandes células B.

O linfoma difuso de grandes células B (LDGC-B) é o subtipo mais comum de NHL na região da cabeça e pescoç $0^{8-11}$. Linfomas de alto grau apresentam alto índice de proliferação celular, células grandes, linfonodomegalias localizadas, agressividade e expectativa de sobrevida de semanas a meses se não tratado ${ }^{1}$. As manifestações clínicas em geral dependem do órgão afetado, porém, alguns sinais comuns incluem redução de peso, sudorese noturna, anorexia; linfadenopatia cervical, inguinal ou axilar ${ }^{4}$. O caso apresentado tratava-se de LDGC-B, sendo portanto incluído no subtipo mais comum na cabeça e pescoço, com aspecto agressivo e rápida evolução, porém envolvia também a coxa esquerda, sem linfonodomegalias ou perda ponderal associadas.

O estágio inicial de LDGC-B é potencialmente curávele,13. O tratamento é baseado no estadiamento e grau do linfoma, estado geral de saúde e a história médica pregressa. A cirurgia geralmente não é indicada ${ }^{6,11}$. 0 tratamento comumente é realizado com esquema quimioterápico - Ciclofosfamida, doxorrubicina, vincristina e prednisona (CHOP), por vezes associado ao rituximab (R-CHOP) $)^{5-7,10}$ associada ou não à radioterapia ${ }^{2,10}$.

\section{CONSIDERAÇÕES FINAIS}

O Linfoma não-Hodgkin extranodal é incomum e muito raramente ocorre na mandíbula, sendo assim, comumente 
confundindo com processos inflamatórios ou infecciosos odontogênicos e para tanto, tratados erroneamente com antibioticoterapia.

Uma anamnese detalhada e investigação clínica com avaliação de exames de imagem e análise de sinais e sintomas locais correlacionando com as condições sistêmicas do paciente, envolvendo uma equipe multidisciplinar é crucial para evitar o atraso no diagnóstico.

O prognóstico e a taxa de sobrevida dependem do diagnóstico precoce e o cirurgião-dentista inserido na equipe multidisciplinar contribui para o diagnóstico diferencial de doenças neoplásica com apresentações inespecíficas que envolvem a cavidade oral, acelerando o início do tratamento oncológico adequado.

\section{REFERÊNCIAS}

1. Corti M, Solari R, Cangelosi D, De Carolis L, Schtirbu R, Lewi D. Oral cavity lymphoma as secondary AIDS-defining neoplasm in a patient on HAART with immune reconstitution. Rev. Soc. Bras. Med. Trop. 2007;40(5):582-584.

2. McClement AP, Healy GM, Redmond CE, Stocker E, Connaghan G, Skehan SJ, et al. Minimally Invasive Diagnosis of Secondary Intracranial Lymphoma. Case Rep Hematol. 2016;6165172, 4 pages.

3. Bugshan A, Kassolis J, Basile J. Primary Diffuse Large B-Cell Lymphoma of the Mandible: Case Report and Review of the Literature. Case Rep Oncol. 2015;8(3):451-455.

4. Neerupakam M, Prakash J, Koduri S, Vishnubhatla T. Non-Hodgkin's Lymphoma of the mandible in HIV patient - A Rare Case Report. Contemp Clin Dent. 2018;9(1):110-113.

5. Castro MS, Ribeiro CM, Carli ML, Pereira AAC, Sperandio FF, Almeida OP, et al. Fatal primary diffuse large B-cell lymphoma of the maxillary sinus initially treated as an infectious disease in an elderly patient: A clinicopathologic report. Gerodontology. 2018;35:59-62.

6. Moin A, Shetty AD. Management of Non-Hodgkin's Lymphoma in Maxillofacial Region with Chemotherapy. Ann Maxillofac Surg. 2017;7(2):312-315.

7. Varun BR, Varghese NO, Sivakumar TT, Joseph AP. Extranodal Non-Hodgkin's Lymphoma of the Oral Cavity: 
A Case Report. Iran J Med Sci July. 2017;42(4):407-411.

8. Kini R, Saha A, Naik V. Diffuse Large B-cell lymphoma of mandible: A case report. Med Oral Patol Oral Cir Bucal. 2009;14(9):e421-424.

9. Kumar MS, Gannepalli A, Chandragiri A, Amarnath K. Diffuse Large B-Cell Lymphoma of Maxilla - A Case Report of Late Relapse. J Clin Diagn Res. 2016;10(4):ZD12-ZD14.

10. Santos PSS, Ferreira ES, Vidote RM, Paes RAP, Freitas RR. Manifestação bucal de linfoma difuso de grandes células B. Rev. Bras. Hematol. Hemoter. 2009;31(6):473-476.

11. Santos FS, Novo Neto JP, Isper MA, Novo LP, Souza Neto R. Linfoma não-Hodgkin de células T na mandíbula. Relato de caso. Rev. Cir. Traumatol. Buco-Maxilo-Fac. 2012;12(2):19-24.

12. Srikant N, Yinti SR, Baliga M, Kini H. A rare spindle-cell variant of non-Hodgkin's lymphoma of the mandible. J Oral Maxillofac Pathol. 2016;20(1):129-132.

13. Araújo LHL, Victorino APOS, Melo AC, Assad DX, Lima DS, Alencar DR, et al. Linfoma Não-Hodgkin de alto grau - Revisão de Literatura. Revista Brasileira de Cancerologia. 2008;54(2):175-183. 